CARPATHIAN JOURNAL OF FOOD SCIENCE AND TECHNOLOGY

journal homepage: http://chimie-biologie.ubm.ro/carpathian_journal/index.html

\title{
DIETARY INTAKES AND HIGH SENSITIVITY CRP (hsCRP) IN ADOLESCENTS WITH OBESITY
}

\author{
Rendi Aji Prihaningtyas ${ }^{1}$, Nur Aisiyah Widjaja ${ }^{1 *}$, Roedi Irawan ${ }^{1}$, Meta Herdiana Hanindita ${ }^{1}$, \\ Boerhan Hidajat ${ }^{1}$ \\ ${ }^{I}$ Department of Child Health, Dr. Soetomo General Hospital, Faculty of Medicine, Universitas Airlangga, \\ Surabaya, Indonesia \\ *nuril08@yahoo.com \\ https://doi.org/10.34302/crpjfst/2019.11.5.12 \\ Article history: \\ Received: \\ 9 March 2019 \\ Accepted: \\ 20 September 2019 \\ Keywords: \\ Obesity; \\ Dietary intake; \\ Adolescents; \\ HsCRP; \\ Inflammatory markers.

\begin{abstract}
Obesity is related to the over-expression of pro-inflammatory cytokines and causes chronic systemic inflammation. The identification of dietary intake at risk of inflammation led to optimal interventions. The aim of this study was to determine the correlation between dietary intake and the inflammatory biomarker in adolescents with obesity.

A cross-sectional study was performed on adolescents with obesity at the Pediatric Nutrition Clinic of Dr Soetomo General Hospital, Surabaya from July to October 2018. Dietary intake was obtained from food recall. The assessment of high sensitivity CRP (hsCRP) was performed using ELISA. Statistical analysis was performed using a correlation test with $\mathrm{p}<0.05$ indicating significance.

A total of 59 adolescents were included, 32 (54.2\%) of which were male and $27(45.8 \%)$ were female. The age range was $13-16$ years. The mean calorie intake was $1955.9 \pm 778$ calories, and the mean hsCRP level was $2308.83 \pm$ $470.95 \mathrm{ng} / \mathrm{ml}$. There was no correlation between total calories, carbohydrate, protein, and fat level intake and hsCRP ( $>0.05)$. No substantial effect of
\end{abstract} \\ dietary intake was found for hsCRP.
}

\section{Introduction}

In developing countries, the prevalence of obesity has increased in all age groups (Rachmi et al., 2017). The cause of obesity is energy imbalance between energy intake and energy expenditure. Diet is important in the development and progression of obesity.

Obesity is related to chronic low-grade inflammation (Lee et al., 2013) and oxidative stress (Paltoglou et al., 2017). Chronic inflammation causes metabolic disease (Castro et al., 2017). Abdominal obesity is a predictive factor of cardiometabolic risk (Amato et al., 2013). Even in obese individuals with a healthy metabolic state, they are at an increased risk of long-term mortality (Kramer et al., 2013).
Over-nutrition is associated with immuneactivation and inflammatory conditions (Lee et al., 2013). Dietary excess produces an accumulation of lipids in adipocytes (GómezHernández et al., 2016). Excess weight has an inflammatory effect (García-Hermoso et al., 2016). However, exercise can reduce the systemic inflammation associated with obesity (Sirico et al., 2018). The complications of obesity are due to metabolic disorder induced by an excessive accumulation of fat, which leads to cardiovascular disease (CVD) and type 2 diabetes mellitus (Morandi and Maffeis, 2014). Diet and nutrition are modifiable variables in obesity (Hale et al., 2015). The aim of this study was to determine the correlation between dietary 
intake and inflammatory biomarkers (hsCRP) in adolescents with obesity.

\section{Materials and methods}

This is a cross-sectional study conducted at The Pediatric Nutrition Clinic of Dr Soetomo General Hospital, Surabaya from July to October 2018.

\subsection{Samples}

Adolescents (age 13-16 years old) with obesity were enrolled. The following exclusion criteria were applied: (a) steroid or medical therapy, (b) hormonal therapy, (c) alcohol consumption, (d) smoking, (e) infection, (f) a medical history including an endocrinology disorder, immunological disorder, cardiovascular disease, or other known chronic pathology, and (h) secondary obesity (having a medical condition that causes gain weight). Health status was obtained through self-report to exclude acute and chronic diseases. The study procedures and objectives were explained to the parents and informed written consent was obtained from all participants before they were enrolled. This study was approved by the Ethics Committee in Health Research of the Dr Soetomo General Hospital, Surabaya.

\subsection{Anthropometric measurements}

Body weight was measured with the patients barefoot and lightly clothed to the nearest $0.1 \mathrm{~kg}$ using calibrated digital scales (Seca, Germany ref. 224 1714009). The barefoot standing height was measured using a fixed stadiometer to the nearest $0.1 \mathrm{~cm}$ (Seca, Germany ref. 224 1714009). Following inclusion, the body mass index (BMI) of all participants was calculated using the following formula: body weight
$(\mathrm{Kg}) /$ height $\left(\mathrm{m}^{2}\right)$; obesity was defined as a BMI greater than the $95^{\text {th }}$ percentile for sex and age based on The United States Centers for Disease Control and Prevention (CDC 2000).

\subsection{Data Collection}

The nutritional profiles of participants were established through food recall using a food model. The total daily intake of calories, carbohydrates, proteins, and fat were calculated.

\subsection{Blood Analyses}

Blood samples were collected in $5 \mathrm{cc}$ aliquots from subjects using tubes containing EDTA. They were centrifuged and shipped to the Laboratory of the Institute of Tropical Disease, Universitas Airlangga for the analysis of inflammatory biomarkers, including hsCRP. Serum levels of hsCRP (ref. CAN-CRP-4360) were measured by specific ELISA kits (Bioassay Technology Laboratory, China) following the manufacturer's instructions.

\subsection{Statistical Analysis}

Data were analyzed using the SPSS software. The value of $p<0.05$ was taken as statistically significant. The Pearson correlation analysis was performed to examine the relationship between calories, protein, carbohydrate, fat, and hsCRP.

\section{Results and Discussion}

A total of 59 adolescents were included in this study, consisting of $32(54.2 \%)$ males and 27 (45.8\%) females. The age range was 13-16 years. Anthropometric measurements, dietary intake, and laboratory characteristics are shown in Table 1

Table 1. Characteristics of subjects

\begin{tabular}{|l|l|}
\hline \multicolumn{1}{|c|}{ Variable } & \multicolumn{1}{c|}{ Mean (SD) } \\
\hline Body weight $(\mathrm{kg})$ & $80.77 \pm 13.35$ \\
\hline Body height $(\mathrm{cm})$ & $158.76 \pm 7.12$ \\
\hline Body Mass Index $\left(\mathrm{kg} / \mathrm{m}^{2}\right)$ & $31.99 \pm 3.67$ \\
\hline
\end{tabular}




\begin{tabular}{|l|l|}
\hline Calories (Kcal/day) & $1955.96 \pm 778.01$ \\
\hline Carbohydrate (Kcal/day) & $1005.95 \pm 421.67$ \\
\hline Protein (Kcal/day) & $361.66 \pm 221.43$ \\
\hline Fat (Kcal/day) & $589.03 \pm 313.25$ \\
\hline hsCRP (ng/ml) & $2308.83(285.79-2941.37)$ \\
\hline
\end{tabular}

The mean hsCRP level was $2308.83 \pm 470.95 \mathrm{ng} / \mathrm{ml}$. The mean calorie intake was $1955.96 \pm 778$ calories. The correlation between dietary intake and hsCRP is given in Table 2.

Table 2. Correlation between dietary intake and inflammatory biomarkers

\begin{tabular}{|c|c|c|c|c|}
\hline Variable & $\begin{array}{c}\text { Total } \\
\text { Calories }\end{array}$ & Carbohydrate & Protein & Fat \\
\hline hsCRP & \multicolumn{5}{|c|}{} \\
\hline $\mathrm{r}$ & -0.167 & -0.178 & -0.015 & -0.164 \\
\hline $\mathrm{p}$ & 0.207 & 0.177 & 0.910 & 0.215 \\
\hline
\end{tabular}

In this study, there were no significant correlations between total calories, carbohydrate, protein, and fat level intake and hsCRP ( $>>0.05$ ) (Table 2.).

Obesity is associated with oxidative stress and aseptic inflammation (Paltoglou et al., 2017). This inflammation is associated with the development of many comorbidities, including metabolic syndrome, cardiovascular disease (CVD) and type 2 diabetes (DeBoer, 2013). Fat cell size and fat cell number are increased in obesity or with a combination of the two (Coelho et al., 2013). Adipose tissue is an endocrine organ secreting adipocytokines, which exert endocrine, paracrine, and autocrine actions, both locally and systemically (Kelishadi et al., 2017). There is an increase in the adipocyte number (hyperplasia) and adipocyte size (hypertrophy), which releases various cytokines such as leptin, adiponectin, tumor necrosis factor-alpha (TNF- $\alpha$ ), interleukin (IL)1, IL-4, IL-6, IL-10, and CRP (Castro et al., 2017). These cytokines induce oxidative stress and inflammation (Ellulu et al., 2017). Elevated inflammatory biomarkers were higher in abdominal adiposity (Steckhan et al., 2016).

HsCRP and TNF- $\alpha$ were significantly higher in obese compare to non-obese individuals (Ayoub et al., 2015). HsCRP is an acute phase protein produced by the liver. HsCRP is negatively associated with anti-oxidation in prepubertal obese boys (Paltoglou et al., 2017). In inflammatory conditions, hsCRP plasma levels are increased and associated with metabolic syndrome, insulin resistance, and cardiovascular disease (DeBoer, 2013). TNF- $\alpha$ is a proinflammatory cytokine produced by macrophages and $\mathrm{T}$ lymphocytes (Kelishadi et al., 2017). Elevated TNF- $\alpha$ is associated with insulin resistance and cardiovascular risk (Khosravi et al., 2013). Higher BMI is associated with a higher TG/HDL ratio and insulin resistance in pre- and post-pubertal children (Olson et al., 2012).

Dietary imbalances characterized by an excessive intake of calories, fat, and carbohydrate are observed in obese subjects (Ayoub et al., 2015). High fat and energy-dense foods are a dietary habit in obesity (Manna and Jain, 2015). The excessive fat and carbohydrate is associated with inflammation (Ayoub et al., 2015). Polyunsaturated fatty acids, an appropriate glycemic index and glycemic load in carbohydrates are associated with improving inflammation in obesity (Lee et al., 2013). Dietary fatty acids influence the expression of the TNF- $\alpha$ cytokine gene and alter TNF- $\alpha$ production (Joffe et al., 2013). The excessive 
intake of carbohydrate and fat is associated with increased TNF- $\alpha$ (Ayoub et al., 2015).

A high protein diet did not improve anthropometric measurements and cardiovascular risk factors (LDL, HDL, insulin, and blood pressure) in obese children (Izadi et al., 2018). However, the energy-restricted high protein diet is associated with a reduction of waist circumference and hsCRP in women (Azadbakht et al., 2013). A low fat diet can reduce CRP (Steckhan et al., 2016).

In this study, no correlation was found between calories, carbohydrate, protein, fat level intake and hsCRP (Figure 1-4.). There was ethnicity difference with another study that showed correlation between dietary intake and inflammatory biomarkers.

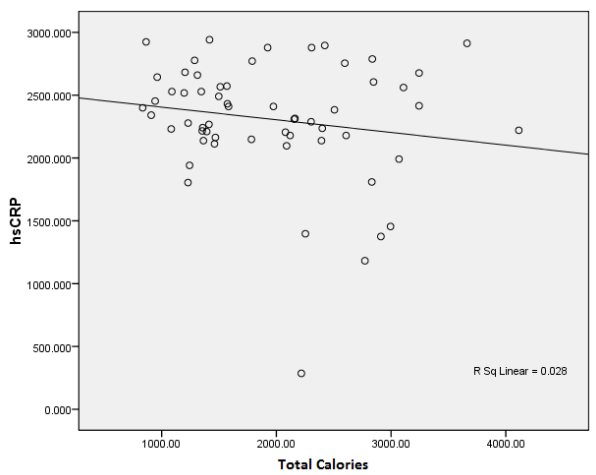

Figure 1. Correlation between Total Calories and hsCRP.

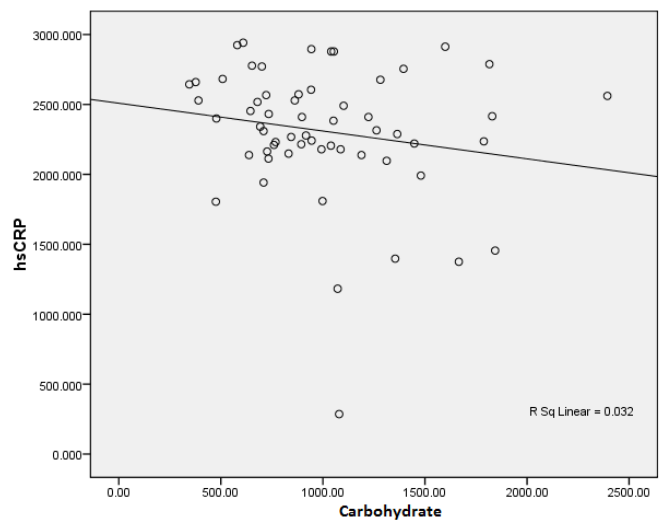

Figure 2. Correlation between Carbohydrate and hsCRP.

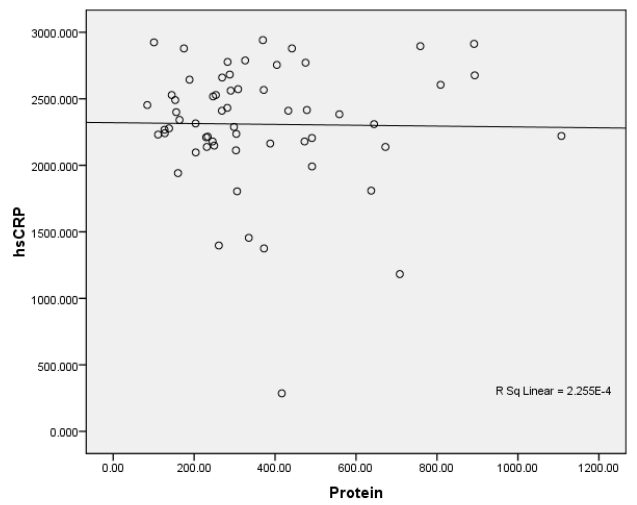

Figure 3. Correlation between Protein and hsCRP.

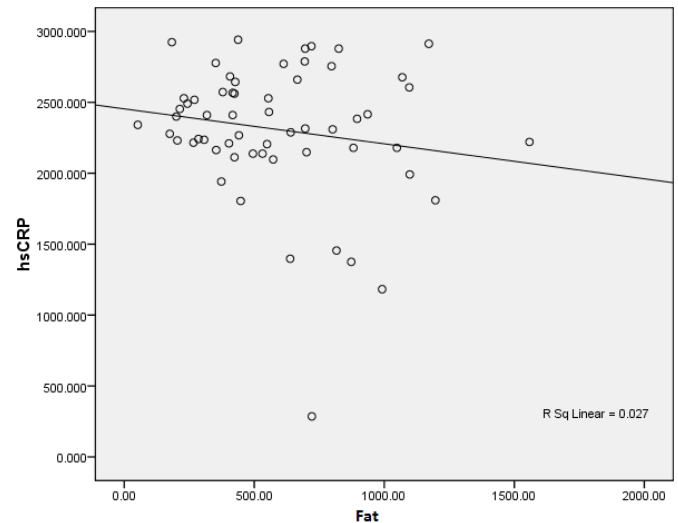

Figure 4. Correlation between Fat and hsCRP.

Dairy product consumption does not influence the biomarkers of inflammation (Labonté et al., 2013). Recent studies in the literature have reported that dietary intake has a positive effect on inflammatory biomarkers in patients with metabolic syndrome (Steckhan et al., 2016). The metabolic syndrome was not examined in this study.

There are limitations on this study. First, the sample size was small. Second, the study only obtained 24 hour recalls once. Third, there was a factor affecting of hsCRP, such as physical activity.

\section{Conclusions}

No effect of dietary intake of calories, carbohydrate, fat, and protein was found for hsCRP. Further studies are needed with larger sample sizes to investigate dietary food composition and its influence on inflammatory biomarkers in adolescents with obesity. 


\section{References}

Amato, M.C., Guarnotta, V., Giordano, C. (2013). Body composition assessment for the definition of cardiometabolic risk. Journal of Endocrinological Investigation, 36(7):537-4.

Ayoub, M., Zouaoui, C., Grira, N., Kochkar, R., Stambouli, N., Bouguerra, C., Zidi, B., Ghazouani, E., Mazigh, C., Aouni, Z. (2015). Correlation between dietary intake and inflammatory biomarkers in a Tunisian obese group. Journal of Biosciences and Medicines, 03, 108-113.

Azadbakht, L., Izadi, V., Surkan, P.J., Esmaillzadeh, A. (2013). Effect of a high protein weight loss diet on weight, highsensitivity C-reactive protein, and cardiovascular risk among overweight and obese women: A parallel clinical trial. International Journal of Endocrinology, 2013, 1-8.

Castro, A.M., Macedo-de la Concha, L.E., Pantoja-Meléndez, C.A. (2017). Low-grade inflammation and its relation to obesity and chronic degenerative diseases. Revista Médica del Hospital General de México, 80, 101-105.

Coelho, M., Oliveira, T., Fernandes, R. (2013). State of the art paper Biochemistry of adipose tissue: an endocrine organ. Archives of Medical Science, 2, 191-200.

DeBoer, M.D. (2013). Obesity, systemic inflammation, and increased risk for cardiovascular disease and diabetes among adolescents: A need for screening tools to target interventions. Nutrition, 29, 379-86.

Ellulu, M.S., Patimah, I., Khaza'ai, H., Rahmat, A., Abed, Y. (2017). Obesity and inflammation: the linking mechanism and the complications. Archives of Medical Science, 4, 851-63.

García-Hermoso, A., Sánchez-López, M., Escalante, Y., Saavedra, J.M., MartínezVizcaíno, V. (2016). Exercise-based interventions and $\mathrm{C}$-reactive protein in overweight and obese youths: a metaanalysis of randomized controlled trials. Pediatric Research, 79, 522-7.
Gómez-Hernández, A., Beneit, N., DíazCastroverde, S., Escribano, Ó. (2016). Differential role of adipose tissues in obesity and related metabolic and vascular complications. International Journal of Endocrinology, 2016, 1-15.

Hale, M.W., Spencer, S.J., Conti, B., Jasoni, C.L., Kent, S., Radler, M.E., Reyes, T.M., Sominsky, L. (2015). Diet, behavior and immunity across the lifespan. Neuroscience \& Biobehavioral Reviews, 58, 46-62.

Izadi, V., Esmaillzadeh, A., Hashemipour, M., Surkan, P.J., Azadbakht, L., Kelishadi, R. (2018). High protein diets do not affect anthropometric indexes and cardiometabolic risk factors among children with excess weight: A randomized controlled trial. Journal of Cardiovascular and Thoracic Research, 10, 95-10.

Joffe, Y., Collins, M., Goedecke, J. (2013). The relationship between dietary fatty acids and inflammatory genes on the obese phenotype and serum lipids. Nutrients, 5, 1672-705.

Kelishadi, R., Roufarshbaf, M., Soheili, S., Payghambarzadeh, F., Masjedi, M. (2017). Association of Childhood Obesity and the Immune System: A systematic review of reviews. Childhood Obesity, 13, 332-46.

Khosravi, R., Ka, K., Huang, T., Khalili, S., Nguyen, B.H., Nicolau, B., Tran, S.D. (2013). Tumor necrosis factor- $\alpha$ and Interleukin-6: Potential inter-organ inflammatory mediators contributing to destructive periodontal disease in obesity or metabolic syndrome. Mediators of Inflammation, 2013, 1-6.

Kramer, C.K., Zinman, B., Retnakaran, R. (2013). Are metabolically healthy overweight and obesity benign conditions? A systematic review and meta-analysis. Annals of Internal Medicine, 159(11), 75869.

Labonté, M.-È., Couture, P., Richard, C., Desroches, S., Lamarche, B. (2013). Impact of dairy products on biomarkers of inflammation: a systematic review of randomized controlled nutritional intervention studies in overweight and obese 
adults. The American Journal of Clinical Nutrition, 97, 706-17.

Lee, H., Lee, I.S., Choue, R. (2013). Obesity, inflammation and diet. Pediatric Gastroenterology, Hepatology \& Nutrition, $16(3), 143-52$.

Manna, P., Jain, S.K. (2015). Obesity, oxidative stress, adipose tissue dysfunction, and the associated health risks: Causes and therapeutic strategies. Metabolic Syndrome and Related Disorders, 13, 423-44.

Morandi, A., Maffeis, C. (2014). Predictors of metabolic risk in childhood obesity. Hormone Research in Paediatrics, 82, 3-11.

Olson, K., Hendricks, B., Murdock, D.K. (2012). The triglyceride to HDL ratio and its relationship to insulin resistance in pre- and post-pubertal children: Observation from the Wausau SCHOOL Project. Cholesterol, 2012, 1-4.

Paltoglou, G., Schoina, M., Valsamakis, G., Salakos, N., Avloniti, A., Chatzinikolaou, A., Margeli, A., Skevaki, C., Papagianni, M., Kanaka-Gantenbein, C., Papassotiriou, I., Chrousos, G.P., Fatouros, I.G., Mastorakos, G. (2017). Interrelations among the adipocytokines leptin and adiponectin, oxidative stress and aseptic inflammation markers in pre- and early-pubertal normalweight and obese boys. Endocrine, 55, 92533.

Rachmi, C.N., Li, M., Alison Baur, L. (2017). Overweight and obesity in Indonesia: prevalence and risk factors - a literature review. Public Health, 147, 20-9.

Sirico, F., Bianco, A., D'Alicandro, G., Castaldo, C., Montagnani, S., Spera, R., Di Meglio, F., Nurzynska, D. (2018). Effects of physical exercise on adiponectin, leptin, and inflammatory markers in childhood obesity: Systematic review and meta-analysis. Childhood Obesity, 14, 207-17.

Steckhan, N., Hohmann, C.-D., Kessler, C., Dobos, G., Michalsen, A., Cramer, H. (2016). Effects of different dietary approaches on inflammatory markers in patients with metabolic syndrome: A systematic review and meta-analysis. Nutrition, 32, 338-48.

\section{Acknowledgment}

The authors thank all of the team that worked on this study. 